\title{
Molecular Interactions in Binary Surfactant Solutions: Effect of pH
}

\author{
Olga Kochkodan ${ }^{1 *}$, Victor Maksin², Nadiya Antraptseva1', Tetyana Semenenko \\ ' Department of General, Organic and Physical Chemistry, National University of Life and Environmental Sciences of Ukraine, \\ Geroiv Oborony Str. 15, 03041, Kyiv, Ukraine \\ 2 Department of Analytical and Bioinorganic Chemistry and Water Quality, National University of Life and Environmental \\ Sciences of Ukraine, Geroiv Oborony Str. 15, 03041, Kyiv, Ukraine \\ * Corresponding author, e-mail: okochkodan@hotmail.com
}

Received: 03 March 2019, Accepted: 07 June 2019, Published online: 25 July 2019

\begin{abstract}
By using surface tension and conductivity measurements, the colloid-chemical properties of the mixtures of cationic hexadecylpyridinium bromide with nonionic Triton X-100 surfactants were investigated both in the bulk solution and at air/solution interface at different $\mathrm{pH}$ values. The composition of mixed micelles and adsorption layers, parameters of molecular interactions in mixed micelles $\beta^{m}$ and adsorption layers $\beta^{\sigma}$, as well as standard free energies of micelle formation $\Delta G^{0}{ }_{\text {mic }}$ and adsorption $\Delta G^{0}{ }_{a d s}$ were calculated. It was found that molecules of the nonionic surfactant presumably dominate in the mixed micelles and adsorption layers. It was shown that $\beta^{m}$ and $\beta^{\sigma}$ have negative values, which indicate the strengthening of intermolecular interactions in the mixed micelles and adsorption layers. Based on the data obtained, it was suggested that ion-dipole interactions are involved in the formation of intermolecular structures between nonionic and cationic surfactants in aqueous solution and at the air-solution interface. It was shown that $\beta^{m}$, $\beta^{\sigma}$ as well as $\Delta G_{\text {mic }}^{0}$ and $\Delta G^{0}{ }_{a d s}$ parameter depends on the solution $\mathrm{pH}$ value. The complex interplay of ion-dipole, protonation and chelation processes, which occur in the surfactant mixtures at different $\mathrm{pH}$ and affect the strength of intermolecular interaction, should be taken into account for data analysis.
\end{abstract}

Keywords

intermolecular interactions, surfactants mixtures, adsorption, Triton X-100, hexadecylpyridinium bromide

\section{Introduction}

Due to surface tension reduction and micelle formation properties, surfactants are used as stabilizers, emulsifiers and foam forming agents in numerous industrial and domestic applications, including mineral flotation, oil recovery, surface coating, wetting, detergency, synthesis of nanoparticles, catalysis, cosmetic and food formulations [1, 2]. Usually, the mixtures of the surfactants are employed in these processes. To that end different surfactants are mixed deliberately to optimize their formulations and performance by using synergetic or antagonistic interactions between the components of the mixture [1-4]. Therefore, understanding the main features of surfactants interactions in the mixed solutions and at interfaces is of vital importance for prediction of the properties and designing the surfactant systems with optimal performance for specific application.

Different theoretical models were suggested to describe properties and interactions in the surfactant systems [5-7].
One of the most widely accepted and used to study the nonideal intermolecular interactions in surfactant mixtures, is the Rubin-Rosen model, which is based on the theory of regular solutions $[2,8,9]$. In this model the intermolecular interactions between the surfactants molecules at interfaces or at micelle formation in the solution are evaluated by using molecular interaction $\beta$ parameters, which can be estimated from surface tension $\left(\beta^{\sigma}\right)$ or critical micelle concentration $\left(\beta^{m}\right)$ data [10].

The effect of surfactant type, molecular structure, length of hydrophobic/hydrophilic chains of the surfactants and the concentration ratios between the components in the mixture on molecular interactions in surfactant systems has been a rich field of research [8-22]. It was found that the mixtures of structurally homologous surfactants usually behave similar to ideal solutions $[1,12,13]$, while the mixtures of structurally different compounds such as 
ionic and nonionic surfactants often show nonideal behavior [8-10, 13-22]. In many cases due to a complex interplay of intermolecular forces between the components, the composition of the mixed micelles and mixed adsorbed layer at the air/solution interface is notably differ compared to the composition of the bulk solution [1, 2, 8-10, 17-21].

Though different parameters, which affect molecular interactions in the surfactants mixtures, have been widely investigated, there are only a few studies related to the influence of solution $\mathrm{pH}$ on micelle formation in multicomponent aqueous mixtures and to composition of the mixed surfactant layers at the air/solution interface [23-25].

Rosen and Zhao [23] evaluated the molecular interaction parameters for mixtures of nonionic $\mathrm{C}_{12} \mathrm{H}_{25}\left(\mathrm{OC}_{2} \mathrm{H}_{4}\right)_{4} \mathrm{OH}\left(\mathrm{C}_{12} \mathrm{EO}_{4}\right)$ and $\mathrm{C}_{12} \mathrm{H}_{25}\left(\mathrm{OC}_{2} \mathrm{H}_{4}\right)_{8} \mathrm{OH}\left(\mathrm{C}_{12} \mathrm{EO}_{8}\right)$ surfactants with anionic sodium alkylsulphates and sodium alkanesulphonates at different concentration and $\mathrm{pH}$ of the solutions. It was found that interaction of polyethylenated nonionic surfactants is stronger with anionic surfactants than with cationic compounds with the same alkyl hydrophobic group. It was shown that the $\beta$ interaction parameter slighly increase with increasing solution $\mathrm{pH}$ from 3.1 to 10.1 for the anionic/nonionic system due to a week cationic charge of the polyoxyethylene chains [23]. In contrast, it was reported later that $\mathrm{pH}$ of the mixed solution did not notably affect molecular interaction parameters for anionic $\mathrm{C}_{12} \mathrm{SO}_{3} \mathrm{Na}$ or $\mathrm{C}_{12} \mathrm{H}_{25}\left(\mathrm{OC}_{2} \mathrm{H}_{4}\right)_{2} \mathrm{SO}_{4} \mathrm{Na}$ mixtures with nonionic surfactants [24].

Goloub et al. [25] studied the micelle formation in amphoteric dodecyldimethylamine oxide/anionic sodium dodecyl sulfate and dodecyldimethylamine oxide/nonionic hexa(ethyleneglycol) mono-n-dodecyl ether mixtures at different $\mathrm{pH}$. Strong interactions between the surfactants were found for the amphoteric/anionic mixtures at $\mathrm{pH} 8$ when dodecyldimethylamine oxide was uncharged. On the other hand, almost ideal surfactants' behavior was observed at $\mathrm{pH} 8$ for the amphoteric/nonionic mixture. The attractive interactions were shown at $\mathrm{pH} 2$ when the amphoteric surfactant exists in its cationic form in the solution.

This study investigates the surface active properties of the nonionic/cationic mixtures of Triton X-100 (TX100) with hexadecylpyridinium bromide (HDPBr). The goal was to evaluate the molecular and thermodynamic interaction parameters in the mixed surfactant solutions at the air/water interface to provide better insight into the molecular interactions between TX100 and HDPBr at different $\mathrm{pH}$ values of the solutions.

\section{Materials and methods}

Cationic surfactant $\mathrm{HDPBr}$ of the general formula $\mathrm{C}_{16} \mathrm{H}_{33} \mathrm{NC}_{5} \mathrm{H}_{5} \mathrm{B \Gamma}$ and nonionic oxyethylated octylphenol TX100 of the molecular formula $\mathrm{C}_{8} \mathrm{H}_{17} \mathrm{C}_{6} \mathrm{H}_{4} \mathrm{O}\left(\mathrm{CH}_{2} \mathrm{CH}_{2} \mathrm{O}\right)_{n} \mathrm{H}$ with the degree of oxyethylation $n=9-10$, were used in the experiments. The surfactants were purchased from Sigma-Aldrich (USA). TX100 was used without additional purification, while $\mathrm{HDPBr}$ was purified by recrystallization from methylethylketone before the experiments. The degree of purification was controlled by the absence of minima at the isotherms of surface tension close to critical micelle concentration (CMC) region. The surfactants solutions were prepared with ultrapure water (Milli-Q Plus, Millipore). The chemical structures of the used surfactants are shown in Fig. 1.

Tensiometric and conductometric methods were used to study the micelle formation in the bulk solution and the interface adsorption from single and mixed surfactant solutions. Surface tension $(\sigma)$ in the solutions was determined by Wilhelmy method by balancing a platinum plate [26] using the tensiometer BT-500 (Analytprilad, Ukraine). The measurements were conducted three times for each solution and the average value was reported. The measurement error was $\pm 0.5 \mathrm{~mJ} \mathrm{~m}^{-2}$. Before measuring the surface tension, the surfactants solutions were kept in the sealed flasks for $24 \mathrm{~h}$.

The specific conductivity $(k)$ of the surfactant solutions was measured by a L-Micro conductivity meter (Chemlab, Ukraine). The volume of the solution was $15 \mathrm{~mL}$, the standard measurement deviation was $\pm 2 \%$.

The mole fraction of TX100 in the mixed surfactant solutions was calculated as:

$\alpha_{T X 100}=\frac{C_{T X 100}}{C_{H D P B r}+C_{T X 100}}$

where $\alpha_{\mathrm{TX} 100}$ is the TX100 mole fraction in the mixed solution, while $C_{H D P B r}$ and $C_{\mathrm{TX} 100}$ are the concentrations of TX100 and HDPB in the surfactant mixture.

The CMC value in the surfactant solutions was evaluated by measuring and plotting the surface tension $(\sigma)$

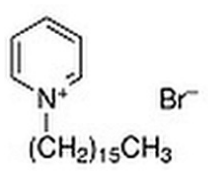

a)

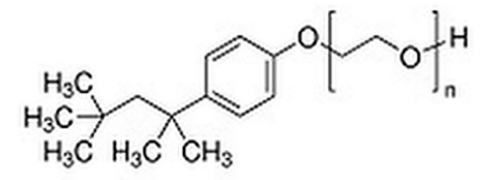

b)
Fig. 1 Chemical structures of $\mathrm{HDPBr}$ (a) and TX100 surfactants (b) 
and specific conductivity $(k)$ of the solutions versus the equilibrium surfactant concentration $(C)$. The $\mathrm{CMC}$ value is defined as the concentration, which corresponds to the break point on the $\sigma(\ln C)$ or $k(C)$ plots.

The $\mathrm{pH}$ of the solutions was measured with a HQ40d $\mathrm{pH}$ meter (Hach, USA). $\mathrm{pH}$ values of the solutions were adjusted by using $1 \times 10^{-3} \mathrm{~mol} \mathrm{dm}^{-3} \mathrm{HCl}$ and $\mathrm{NaOH}$.

\section{Results and discussion}

Fig. 2 presents the isotherms of the surface tension of individual surfactants and their mixtures at solution $\mathrm{pH}$ values of $3.3,6.7$ and 9.1 .

As seen in Fig. 2, the isotherms of surface tension for the surfactant mixtures are mainly located between the isotherms for the single surfactants solutions at all $\mathrm{pH}$ values studied. With an increase of the nonionic surfactant's content in the mixture $\left(\alpha_{\mathrm{TX} 100}\right)$ from 0.2 to 0.8 and at the same total surfactants concentration, the surface tension of the mixture decreases. The lowest surface tension is achieved in the HDPBr/TX100 system at $\alpha_{\mathrm{TX} 100}=0.8$ irrespective to $\mathrm{pH}$ value of the mixed solutions. It should be mentioned that after adding TX100 to HDPBr solution, $\mathrm{CMC}$ value of the binary mixture was lower compared to CMC for the single HDPBr solution.

Dependencies of specific conductance versus $\mathrm{HDPBr}$ concentration in single and mixed surfactants solutions at pH 3.3 are shown in Fig. 3. Similar plots (not presented) were obtained at $\mathrm{pH} 6.7$ and 9.1.

As seen in Fig. 3 the specific conductivity of mixed HDPBr/TX100 solutions is the same as for HDPBr solutions. It means that the presence of non-ionic molecules has no effect on the conductivity of the mixed solutions.

Taking into account the obtained surface tension (Fig. 2) and conductance (Fig. 3) data, the main colloid-chemical characteristics of HDPBr and TX100 surfactants were calculated and presented in Table 1.

The surface concentration or superficial surfactant's excess $\left(\Gamma^{\sigma}\right)$ at interface is a quantitative parameter, which related to the surfactant's surface activity. The Gibbs adsorption equation was used to calculate $\Gamma^{\sigma}[1,26]$ :
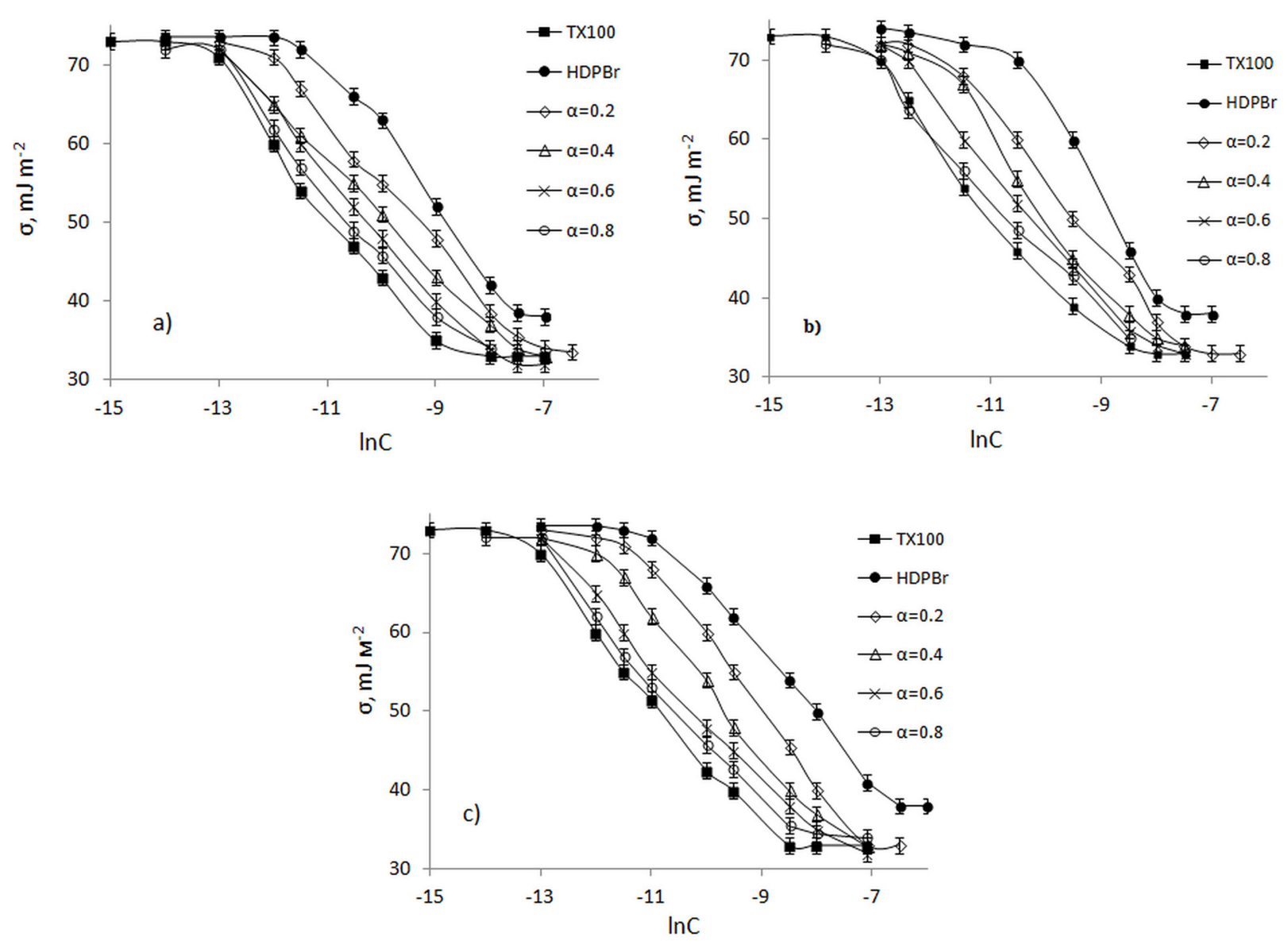

Fig. 2 Surface tension isotherms of the single surfactants solutions and TX100/HDPBr mixtures at different TX100 molar fraction $(\alpha)$ in the mixture at $\mathrm{pH} 3.3$ (a), 6.7 (b) and 9.1 (c). Temperature $20{ }^{\circ} \mathrm{C}$. 
Table 1 CMC, surface excess $\Gamma_{\text {max }}^{\sigma}$, area per molecule $S_{0}$ in the saturated adsorbed layer, the standard free energies of micelle formation $\Delta G^{0}{ }_{m i c}$

\begin{tabular}{lccccc}
\multicolumn{4}{c}{ and adsorption $\Delta G_{a d s}^{0}$ for the used surfactants. } \\
\hline Surfactant & $\mathrm{CMC} \times 10^{3}, \mathrm{~mol} \mathrm{dm}^{-3}$ & $\Delta G^{0}{ }_{m i c}, \mathrm{~kJ} \mathrm{~mol}^{-1}$ & $\Gamma_{\max }^{\sigma}, \times 10^{6}, \mathrm{~mol} \mathrm{~m}^{-2}$ & $S_{o}, \mathrm{~nm}^{2}$ & $\Delta G_{a d s}^{0}, \mathrm{~kJ} \mathrm{~mol}^{-1}$ \\
\hline TX100 & $0.24 \pm 0.02$ & $-30.7 \pm 0.5$ & $5.54 \pm 0.30$ & $0.33 \pm 0.01$ & $-32.1 \pm 0.5$ \\
HDPB & $0.67 \pm 0.03$ & $-23.6 \pm 0.4$ & $3.76 \pm 0.15$ & $0.61 \pm 0.02$ & $-25.4 \pm 0.4$ \\
\hline
\end{tabular}
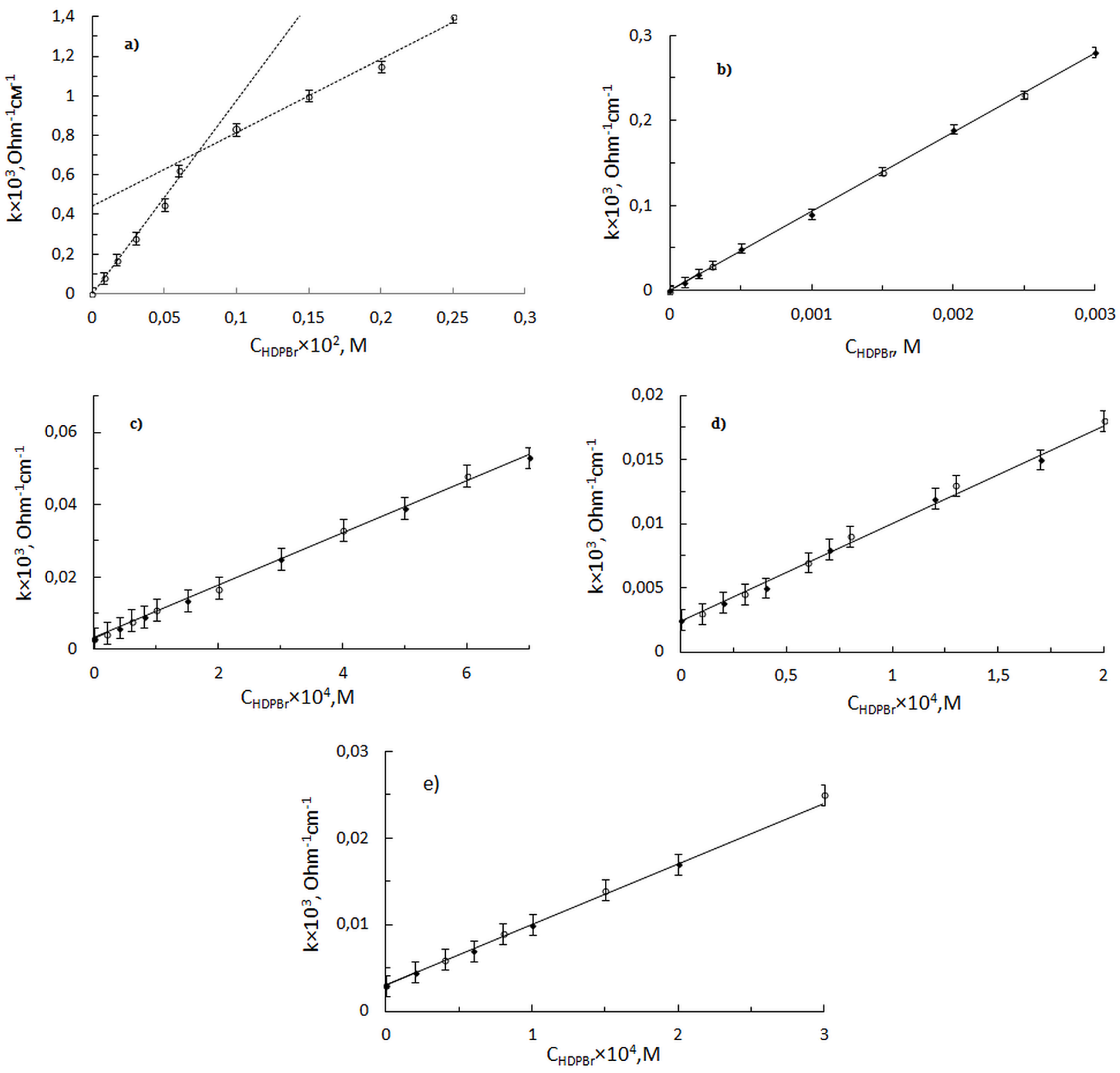

Fig. 3 Specific conductivity of single HDPBr solutions (a) and HDPBr/TX100 mixtures at different TX100 mole fraction $\left(\alpha_{\mathrm{TX} 100}\right)$ : $0.2(\mathrm{~b})$,

0.4 (c), 0.6 (d) and 0.8 (e). For comparison, specific conductivity of single HDPBr solutions (o) is also shown in Fig. $3(\mathrm{~b})-(\mathrm{e}) . \mathrm{pH}=3.3$.

$\Gamma^{\sigma}=-\frac{C}{i R T} \frac{d \sigma}{d C}=-\frac{1}{i R T} \frac{d \sigma}{d \ln C}$

where $i$ is 1 for a nonionic surfactant, while 2 is for an ionic surfactants, respectively.

$\Gamma^{\sigma}$ reaches its maximum value at $d \sigma / d \ln C=\max$, and hence $\Gamma^{\sigma}=\Gamma_{\max }^{\sigma}$.
The area that is occupied by the surfactant molecule in the saturated adsorption layer $S_{0}\left(\mathrm{~nm}^{2}\right)$ was calculated by the Eq. (3) [26]:

$$
S_{0}=\frac{10^{18}}{\Gamma_{\max }^{\sigma} N_{A}}
$$


where $N_{A}$ is the Avogadro number and $\Gamma^{\sigma}{ }_{\max }$ is the maximal adsorption value.

Fig. 4 shows the dependence of the surface tension versus molar composition of HDPBr/TX100 mixture at different $\mathrm{pH}$ values of the mixed solutions. As seen in this Figure, at the same $\alpha_{\text {TX100 }}$ value the surface tension of HDPBr/ TX100 mixture at different $\mathrm{pH}$ of the solutions is the lowest at $\mathrm{pH} 6.7$ and then increase at $\mathrm{pH} 3.3$ and 9.1 respectively. These findings, as it will be detailed when discussing data in Table 2 and 3, might be explained by the protonation of the oxyethylene chain of the nonionic surfactant in the acidic solution [10] on the one hand and chelation of polyoxyethylene chain with sodium ions in the alkiline solution on the other hand [27], which affect the intermolecular interactions between TX100 and HDPBr molecules.

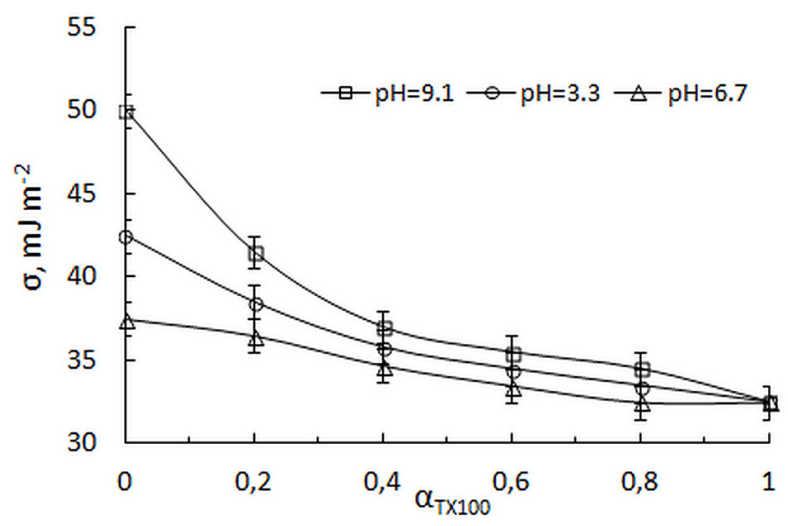

Fig. 4 The dependences of the surface tension versus composition of the mixed HDPBr/TX100 solutions at different $\mathrm{pH}$ and at total concentration of the surfactant mixtures $3.35 \times 10^{-4} \mathrm{~mol} \mathrm{dm}^{-3}$
The Rubin-Rosen model [8, 9], which is based on the theory of regular solutions, was used to calculate the quantitative characteristics of micelle formation and adsorption in the surfactant mixture. With this model, micelle formation is considered as a second-order phase transition process. Composition of mixed micelles and adsorption layers, parameters of molecular interaction in micelles $\beta^{m}$ and in adsorption layers $\beta^{\sigma}$, as well as standard free energies of micelle formation $\Delta G_{\text {mic }}$ and adsorption $\Delta G_{a d s}$ were calculated based on experimental CMC and surface tension data in HDPBr/TX100 surfactant mixtures.

The micelar parameter of intermolecular interaction $\beta^{m}$ was calculated according to the Eq. (4) [8]:

$$
\beta^{m}=\frac{\ln \left(\alpha_{1} C M C / X_{1}^{m} C M C_{1}\right)}{\left(1-X_{1}^{m}\right)^{2}}
$$

where $\mathrm{CMC}$ and $\mathrm{CMC}_{1}$ are $\mathrm{CMC}$ values for the surfactant mixture and surfactant 1 , while $\alpha_{1}$ and $X_{1}^{m}$ correspond to the molar surfactant 1 fractions in the bulk solution and mixed micelle, respectively.

To calculate the composition of mixed micelles, specifically the molar fraction of surfactant $1\left(X_{1}^{m}\right)$ in the micelle, Eq. (5) was used $[8,9]$ :

$$
\left(X_{1}^{m}\right)^{2} \ln \left(\frac{\alpha_{1} C M C}{X_{1}^{m} C M C_{1}}\right)=\left(1-X_{1}^{m}\right)^{2} \ln \left(\frac{\left(1-\alpha_{1}\right) C M C}{\left(1-X_{1}^{m}\right) C M C_{2}}\right)
$$

where $X_{1}^{m}$ and $\alpha_{1}$ are the micellar and bulk molar fractions of surfactant 1 , while $\mathrm{CMC}_{1}, \mathrm{CMC}_{2}$ and $\mathrm{CMC}$

Table 2 TX100 micellar fraction $X^{m}$, intermolecular parameter $\beta^{m}$, CMC and $\Delta G_{m i c}$ values in $\mathrm{HDPBr} / \mathrm{TX} 100$ surfactant mixtures at different $\mathrm{pH}$

\begin{tabular}{lcccc}
\hline \multicolumn{1}{c}{$\alpha$} & 0.2 & 0.4 & 0.6 & 0.8 \\
\hline$X^{m}$ & $0.63 \pm 0.01$ & $0.66 \pm 0.01$ & $0.72 \pm 0.01$ & $0.77 \pm 0.02$ \\
$\beta^{m}$ & $-2.3 \pm 0.1$ & $-2.1 \pm 0.1$ & $-2.6 \pm 0.1$ & $-2.8 \pm 0.1$ \\
$C M C \times 10^{3}, \mathrm{~mol} \mathrm{dm}^{-3}$ & $0.60 \pm 0.03$ & $0.64 \pm 0.03$ & $0.33 \pm 0.02$ & $0.27 \pm 0.02$ \\
$-\Delta G^{0}{ }_{\text {mic }} \mathrm{kJ} \mathrm{mol}^{-1}$ & $18.08 \pm 0.35$ & $17.07 \pm 0.32$ & $19.51 \pm 0.37$ & $20.01 \pm 0.40$ \\
\hline \multicolumn{5}{c}{$\mathrm{pH} 6.7$} \\
\hline$X^{m}$ & $0.76 \pm 0.02$ & $0.77 \pm 0.02$ & $0.75 \pm 0.02$ & $0.79 \pm 0.02$ \\
$\beta^{m}$ & $-2.5 \pm 0.1$ & $-2.8 \pm 0.1$ & $-2.4 \pm 0.1$ & $-3.1 \pm 0.1$ \\
$C M C \times 10^{3}, \mathrm{~mol} \mathrm{dm}^{-3}$ & $0.51 \pm 0.03$ & $0.34 \pm 0.02$ & $0.26 \pm 0.02$ & $0.24 \pm 0.02$ \\
$-\Delta G^{0}{ }_{m i c}, \mathrm{~kJ} \mathrm{~mol}^{-1}$ & $18.50 \pm 0.35$ & $19.45 \pm 0.37$ & $20.29 \pm 0.40$ & $20.46 \pm 0.41$ \\
\hline \multicolumn{5}{c}{$\mathrm{pH} \mathrm{9.1}$} \\
\hline$X^{m}$ & $0.67 \pm 0.01$ & $0.65 \pm 0.01$ & $0.66 \pm 0.01$ & $0.69 \pm 0.01$ \\
$\beta^{m}$ & $-1.6 \pm 0.1$ & $-1.8 \pm 0.1$ & $-2.1 \pm 0.1$ & $-2.3 \pm 0.1$ \\
$C M C \times 10^{3}, \mathrm{~mol} \mathrm{dm}^{-3}$ & $0.58 \pm 0.03$ & $0.83 \pm 0.04$ & $0.64 \pm 0.03$ & $0.52 \pm 0.03$ \\
$-\Delta G^{0}{ }_{\text {mic }} \mathrm{kJ} \mathrm{mol}^{-1}$ & $18.15 \pm 0.35$ & $17.01 \pm 0.32$ & $17.90 \pm 0.33$ & $18.43 \pm 0.35$ \\
\hline
\end{tabular}


Table 3 TX100 mole fraction in the mixed adsorption layer $X^{\sigma}$, intermolecular parameter $\beta^{\sigma}$ and $\Delta G_{a d s}^{0}$ values in HDPBr/TX100 mixtures at $\sigma=40 \mathrm{~mJ} \mathrm{~m}^{-2}$

\begin{tabular}{lcccc}
\hline \multicolumn{1}{c}{$\alpha$} & 0.2 & 0.4 & 0.6 & 0.8 \\
\hline$X^{\sigma}$ & $0.78 \pm 0.02$ & $0.80 \pm 0.02$ & $0.85 \pm 0.02$ & $0.89 \pm 0.02$ \\
$\beta^{\sigma}$ & $-1.3 \pm 0.1$ & $-1.8 \pm 0.1$ & $-3.2 \pm 0.1$ & $-3.0 \pm 0.1$ \\
$-\Delta G_{a d s}^{0}, \mathrm{~kJ} \mathrm{~mol}^{-1}$ & $18.05 \pm 0.25$ & $19.37 \pm 0.29$ & $20.03 \pm 0.30$ & $21.41 \pm 0.32$ \\
\hline & & $\mathrm{pH} 6.7$ & \\
\hline$X^{\sigma}$ & $0.70 \pm 0.01$ & $0.75 \pm 0.02$ & $0.78 \pm 0.02$ & $0.78 \pm 0.02$ \\
$\beta^{\sigma}$ & $-2.1 \pm 0.1$ & $-3.1 \pm 0.1$ & $-5.5 \pm 0.2$ & $-5.8 \pm 0.2$ \\
$-\Delta G^{0}{ }_{a d s}, \mathrm{~kJ} \mathrm{~mol}^{-1}$ & $19.23 \pm 0.29$ & $20.50 \pm 0.31$ & $21.44 \pm 0.32$ & $22.35 \pm 0.33$ \\
\hline & & $\mathrm{pH} 9.1$ & \\
\hline$X^{\sigma}$ & $0.67 \pm 0.01$ & $0.65 \pm 0.01$ & $0.69 \pm 0.01$ & $0.82 \pm 0.02$ \\
$\beta^{\sigma}$ & $-2.3 \pm 0.1$ & $-3.3 \pm 0.1$ & $-5.7 \pm 0.2$ & $-5.9 \pm 0.2$ \\
$-\Delta G_{a d s}^{0}, \mathrm{kJmol}^{-1}$ & $19.66 \pm 0.29$ & $20.74 \pm 0.31$ & $21.85 \pm 0.33$ & $21.88 \pm 0.33$ \\
\hline
\end{tabular}

correspond to $\mathrm{CMC}$ values for surfactant 1,2 and the surfactant mixture, respectively.

Thus, to calculate the composition of mixed micelles and parameters of intermolecular interaction for a mixture at given bulk composition, it is sufficient to experimentally determine the CMC values for a mixture and for singe surfactant solutions. It should be noted that $\beta^{m}$ parameter is the main quantitative characteristic of the nonideal behavior of a surfactant at micelle formation. The signs $(+)$ and $(-)$ of $\beta^{m}$ parameters correspond to the positive and negative deviation from the ideal behavior, while the absolute value describes the strength of intermolecular interactions. Negative $\beta^{m}$ values point to attractive interactions between the surfactant molecules, while positive values indicate the repulsive intermolecular interactions.

It was shown that in order to evaluate the standard free energy of micelle formation $-\Delta G^{0}$ mic for diluted mixed surfactants solutions at concentrations less than $1 \times 10^{-2} \mathrm{~mol} \mathrm{dm}^{-3}$, Eq. (6) can be used [28]:

$\Delta G_{m i c}^{0}=R T \ln C M C$.

The surfactant ability to adsorb at the air-solution interface can be also characterized by the change of standard free energy adsorption $\Delta G^{0}{ }_{a d s}$. Assuming that the bulk surfactant concentration, which corresponds to formation of the saturated adsorption layer, does not exceed $1 \times 10^{-2} \mathrm{~mol} \mathrm{dm}^{-3}, \Delta G_{\text {ads }}^{0}$ can be calculated from the RosenAronson equation [1]:

$$
\Delta G_{a d s}^{0}=2.303 R T \log \frac{C}{\varpi}-N_{A} \pi A_{m}
$$

where $A_{m}$ is area per molecule at air/solution boundary $\left(\mathrm{m}^{2}\right), \pi$ is the surface tension at concentration $C$, at which $A_{m}$ value is reached, $\omega$ is a number of water moles per $\mathrm{L}$. $\Delta G^{0}{ }_{a d s}$ calculation in this case refers to a given value of the surface tension.

The standard free energy adsorption $\Delta G^{0}$ ads values for TX100 and HDPBr surfactants, which were calculated according to the Rosen-Aronson equation, are shown in Table 1. The calculations were conducted assuming the formation of the saturated surface layer: $\Gamma^{\sigma}=\Gamma_{\max }^{\sigma}$, $\mathrm{C}=C M C, A_{m}=S_{0}$. The obtained $\Delta G^{0}{ }_{a d s}$ values prove that the nonionic TX100 surfactant had a higher absorption capacity and, thus higher surface activity than the cationic HDPBr counterpart.

The results of calculation of the composition of mixed micelles, micellar intermolecular interaction parameter $\beta^{m}$ and changes of the standard free energy of micelle formation $\Delta G^{0}{ }_{m i c}$ are presented in Table 2 . As seen, $\beta^{m}$ parameter has negative values, which indicate notable intermolecular interactions between the components in the binary mixture. It is known that the attractive dispersion forces between hydrophobic parts of the surfactants molecules largely contribute to their intermolecular interactions [1]. Also, the possibility of ion-dipole interactions between the hydrophilic groups of cationic and nonionic surfactants was previously reported [29]. Oxygen atoms in polyoxyethylene chain of nonionic surfactant possess unpaired electrons, which can coloumbically attract to the ion of the cationic surfactant [30]. The schematic presentation of the mixed HDPBr/TX100 micelle in aqueous solution is shown in Fig. 5. 
As seen in Table 2, $\beta^{m}$ parameter (by its absolute value) is higher in the neutral solution ( $\mathrm{pH}$ 6.7) compared to acidic solution ( $\mathrm{pH}$ 3.3). This is obviously, due to protonation of the oxyethylene chain of the nonionic surfactant at low pH value as was suggested by Zhou and Rosen [10]. Such protonation will result in electrostatic repulsion between TX100 and HDPBr molecules and reduce $\beta^{m}$ values in the acidic solution. Interestingly that $\beta^{m}$ and $\Delta G^{0}{ }_{\text {mic }}$ values decrease when solution $\mathrm{pH}$ increases from $\mathrm{pH} 6.7$ to 9.1. These findings might be explained by reducing of the ion-dipole interaction between HDPBr and TX100 molecules due to adding some sodium ions during $\mathrm{pH}$ adjustment with $\mathrm{NaOH}$. It was shown previously that alkali metal ions, which are less hydrated than $\mathrm{H}^{+}$ions, strongly chelate the oxygen atoms of polyexyethylene chains [27]. In fact, the sinergetic effects in the mixtures of anionic and nonionic surfactants are explained by formation of such complexes [27]. In our case the chelation of sodium ions with polyoxyethylene chain of the nonionic surfactant with reduce the ion-dipole interactions between HDPBr and TX100 molecules in the alkaline solution ( $\mathrm{pH}$ 9.1) compared to the interactions in the neutral solution $(\mathrm{pH} 6.7)$.

It should be mentioned that molecules of the nonionic surfactant presumably dominate in the mixed micelles. The TX100 micellar fraction is the highest at $\alpha_{\mathrm{TX100}}=0.6-0.8$ and the micellar fraction value increases to a small extent with an increase in TX100 content in the bulk solution. With increasing of $\mathrm{pH}$ of the solution, $\beta^{m}$ and $\Delta G^{0}{ }_{\text {mic }}$ values for TX100/ $\mathrm{HDPBr}$ mixture are reduced. This indicates that ion-dipole interactions are involved in the formation of intermolecular structures between the cationic and nonionic surfactants.

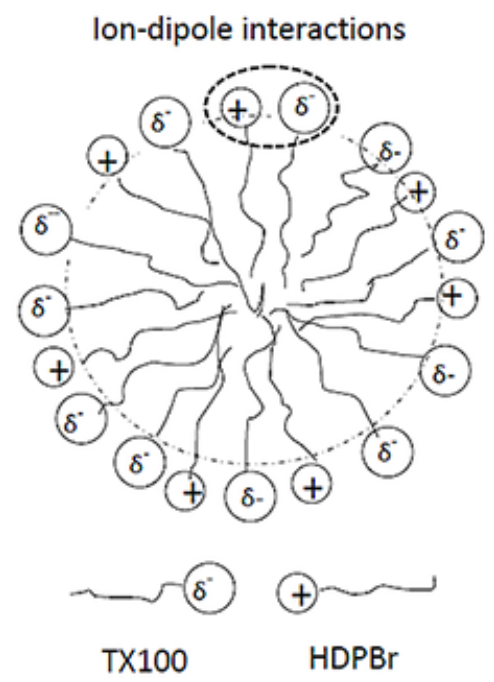

Fig. 5 Schematic presentation of the mixed HDPBr/TX100 micelle in aqueous solution
Similar calculations were conducted for the mixed adsorption layer at air/solution boundary. The parameter of intermolecular interaction in the adsorption layer $\beta^{\sigma}$ was estimated as [8, 24]:

$\beta^{\sigma}=\left(\frac{\ln \left(\left(\alpha_{1} C / X_{1}^{\sigma} C_{1}^{0}\right)\right.}{\left(1-X_{1}^{\sigma}\right)^{2}}\right)$

where $C_{1}^{0}$ and $C$ are the bulk concentrations of the surfactant 1 and the binary solutions with the identical surface tension, while $\alpha_{1}$ and $X_{1}^{\sigma}$ are the molar surfactant 1 fractions in the bulk solution and in the surface layer.

The composition of the adsorption layer was calculated from Eq. (9) [1, 7]:

$$
\left(X_{1}^{\sigma}\right)^{2} \ln \left(\frac{\alpha_{i} C}{C_{1}^{0} X_{1}^{\sigma}}\right)=\left(1-X_{1}^{\sigma}\right)^{2} \ln \left(\frac{\alpha_{2} C}{C_{2}^{0}\left(1-X_{1}^{\sigma}\right)}\right)
$$

where $C_{1}^{0}, C_{2}^{0}$ and $C$ are bulk concentrations of surfactants 1, 2 and binary solutions with the identical surface tension, while $\alpha_{1}$ and $X_{1}^{\sigma}$ correspond to molar fractions of surfactant 1 in the solution and in the surface layer.

Thus, having estimated from the experimental data the concentration of the mixture and the individual surfactants, at which the given value of the surface tension is achieved, one can calculate the composition of the mixed adsorbed layer at a given value of the surface tension.

As seen in Table 3, the mixed adsorption layers are enriched with TX100 component, probably because of its higher surface activity at the air/solution interface compared to HDPBr counterpart. The analysis of interactions between TX100 and HDPBr molecules in the adsorption layer shows that $\beta^{\sigma}$ has negative values at all studied $\mathrm{pH}$. This can be explained by reducing of the electrostatic repulsive forces between the similarly charged $\mathrm{HDPBr}$ molecules due to incorpopation of nonionic TX100 molecules in the adsorption layer.

The intermolecular parameter $\beta^{\sigma}$ and $\Delta G^{0}$ ads increase (by their absolute values) in the transition from acidic ( $\mathrm{pH} 3.3$ ) to neutral ( $\mathrm{pH}$ 6.7) solution (Table 3). This is obviously due to increasing of ion-dipole interaction between HDPBr' cations and some oxygen atoms in the polyoxyethylene chain of TX100 surfactant as was discussed above for micelle formation. At $\mathrm{pH} 3.3$ the ion-dipole interactions are weaker because of possible protonation of the oxyethylene chain of the nonionic surfactant [10]. Decreasing of $\beta^{\sigma}$ and $\Delta G_{\text {ads }}^{0}$ values with an increase of solution $\mathrm{pH}$ from 6.7 to 9.1 might be explained by reducing of the ion-dipole interaction between HDPBr and TX100 molecules due to chelation of sodium ions with oxygen atoms of polyexyethylene chains [27]. 


\section{Conclusions}

Based on surface tension and conductivity data, it was shown that the mixed micelles in HDPBr/TX100 solutions compose mainly of the nonionic component. By using the Rubin-Rosen model, the composition of mixed micelles and adsorption layers, parameters of molecular interactions in mixed micelles $\beta^{m}$ and adsorption layers $\beta^{\sigma}$, as well as standard free energies of micelle formation $\Delta G^{0}{ }_{\text {mic }}$ and adsorption $\Delta G^{0}{ }_{a d s}$ were calculated. It was found that the mixed HDPBr/TX100 adsorbtion layer at the air/solution interface is enriched with TX100 molecules, which have higher surface activity compared to HDPBr counterpart. Based on the data obtained, it was suggested that ion-dipole interactions are involved in the formation of intermolecular structures between nonionic and cationic surfactants in aqueous solution and at the air-solution interface.

\section{References}

[1] Rosen, M. J., Kunjappu, J. M. "Surfactants and interfacial phenomena", Jon Willey and Sons Inc., New Jersey, USA, 2012.

[2] Penfold, J., Staples, E. J., Tucker, I., Thomas, R. K. "The structure of mixed surfactants at the air-water interface", Colloids and Surfaces A: Physicochemical and Engineering Aspects, 155(1), pp. 11-26, 1999. https://doi.org/10.1016/S0927-7757(98)00393-8

[3] Chen, L., Xiao, J.-X., Ruan, K., Ma, J. "Homogeneous solutions of equimolar mixed cationic-anionic surfactants", Langmuir, 18(20), pp. 7250-7252, 2002.

https://doi.org/10.1021/la025878d

[4] Bagheri, A., Khalili, P. "Synergism between non-ionic and cationic surfactants in a concentration range of mixed monolayers at an air-water interface", RSC Advances, 7, pp. 18151-18161, 2017. https://doi.org/10.1039/C6RA27382C

[5] Maeda, H. A. "A Simple Thermodynamic Analysis of the Stability of Ionic/Nonionic Mixed Micelles", Journal of Colloid and Interface Science, 172(1), pp. 98-105, 1995.

https://doi.org/10.1006/jcis.1995.1230

[6] Bergström, M., Eriksson, J. C. "A Theoretical Analysis of Synergistic Effects in Mixed Surfactant Systems", Langmuir, 16(18), pp. 7173-7181, 2000.

https://doi.org/10.1021/la000397k

[7] Matsubara, H., Ohta, A., Kameda, M., Ikeda, N., Aratono, M. "Interaction between Ionic and Nonionic Surfactants in the Adsorbed Film and Micelle. Dodecylammonium Chloride and Tetraethylene Glycol Monooctyl Ether", Langmuir, 16(20), pp. 7589-7596, 2000.

https://doi.org/10.1021/la991499h

[8] Hua, X. Y., Rosen, M. J. "Synergism in binary mixtures of surfactants: I. Theoretical analysis", Journal of Colloid and Interface Science, 90(1), pp. 212-219, 1982.

https://doi.org/10.1016/0021-9797(82)90414-3
It was shown that $\beta^{m}, \beta^{\sigma}$ as well as $\Delta G^{0}{ }_{m i c}$ and $\Delta G^{0}$ ads parameters depend on the solution $\mathrm{pH}$ value. These parameters have the highest absolute value in the surfactant mictures at $\mathrm{pH}$ 6.7, where the ion-dipole interactions between the TX100 and HDPBr molecules are the most pronounced. The weakening of intermolecular interactions in acidic ( $\mathrm{pH}$ 3.3) and alkaline ( $\mathrm{pH}$ 9.1) surfactants mixtures is obviously, due to the protonation of the polyoxyethylene units of the nonionic surfactant in the acidic solution and their chelation with sodium ions in the alkaline solution. Both these effects reduce the ion-dipole interaction between the TX100 and HDPBr molecules.

\section{Acknowlegement}

The work is supported by the Grant from Ministry of Education and Science of Ukraine (Grant No. 110/103-F).

[9] Rosen, M. J., Sulthana, S. B. "The Interaction of Alkylglycosides with Other Surfactants", Journal of Colloid and Interface Science, 239(2), pp. 528-534, 2001.

https://doi.org/10.1006/jcis.2001.7537

[10] Zhou, Q., Rosen, M. J. "Molecular Interactions of Surfactants in Mixed Monolayers at the Air/Aqueous Solution Interface and in Mixed Micelles in Aqueous Media: The Regular Solution Approach", Langmuir, 19(11), pp. 4555-4562, 2003. https://doi.org/10.1021/1a020789m

[11] Clint, J. H. "Micellisation of mixed nonionic surface active agents", Journal of the Chemical Society, Faraday Transactions 1: Physical Chemistry in Condensed Phases, 71(1), pp. 1327-1334, 1975. https://oi.org/10.1039/F19757101327

[12] Scamehorn, J. F. "An Overview of Phenomena Involving Surfactant Mixtures", In: Book editor with Scamehorn J. F. (ed.) Phenomena in Mixed Surfactant Systems, ACS Symposium Series 311, ACS, Washington, DC, USA, 1986, pp. 1-27. https://doi.org/10.1021/bk-1986-0311

[13] Janczuk, B., Zdziennicka, A., Wojcik, W. "The properties of mixtures of two cationic surfactants in water at water/air interface", Colloids and Surfaces A: Physicochemical Engineering Aspects, 220(1-3), pp. 61-68, 2003. https://doi.org/10.1016/S0927-7757(03)00060-8

[14] Szymczyk, K., Janczuk, B. "The adsorption at solution-air interface and volumetric properties of mixtures of cationic and nonionic surfactants", Colloids and Surfaces A: Physicochemical Engineering Aspects, 293(1-3), pp. 39-50, 2007. https://doi.org/10.1016/j.colsurfa.2006.07.006

[15] Zdziennicka, A., Szymczyk, K., Krawczyk, J., Janczuk, B. "Activity and thermodynamic parameters of some surfactants adsorption at the water-air interface", Fluid Phase Equilibria, 318, pp. 25-33, 2012.

https://doi.org/10.1016/j.fluid.2012.01.014 
[16] Wang, Y., Marques, E. F., Pereira, C. M. "Monolayers of gemini surfactants and their catanionic mixtures with sodium dodecyl sulfate at the air-water interface: Chain length and composition effects", Thin Solid Films, 516(21), pp. 7458-7466, 2008. https://doi.org/10.1016/j.tsf.2008.03.029

[17] Geng, T., Zhang, C., Jiang, Y., Ju, H., Wang, Y. "Synergistic effect of binarymixtures contained newly cationic surfactant: Interaction, aggregation behaviors and application properties", Journal of Molecular Liquids, 232, pp. 36-44, 2017. https://doi.org/10.1016/j.molliq.2017.02.055

[18] Bakshi, M. S., Singh, J., Singh, K., Kaur, G. "Mixed micelles of cationic 12-2-12 gemini with conventional surfactants: the head group and counterion effects", Colloids and Surfaces A: Physicochemical and Engineering Aspects, 237(1-3), pp. 61-71, 2004. https://doi.org/10.1016/j.colsurfa.2004.01.030

[19] Gharibi, H., Razavizadeh, B. M., Hashemianzaheh, M. "New approach for the studies of physicochemical parameters of interaction of Triton X-100 with cationic surfactants", Colloids and Surfaces A: Physicochemical and Engineering Aspects, 174(3), pp. 375-386, 2000 . https://doi.org/10.1016/S0927-7757(00)00542-2

[20] Javadian, S., Kakeman, J. "Intermicellar interaction in surfcatant solutions: a review study", Journal of Molecular Liquids, 242, pp. 115-128, 2017. https://doi.org/10.1016/j.molliq.2017.06.117

[21] Cirin, D., Krstonosic, V., Sazdanic, D. "Synergism and antagonism in mixed monolayers: Brij S20/poloxamer 407 and Triton X-100/poloxamer 407 mixtures", Fluid Phase Equilibria, 473, pp. 220-225, 2018. https://doi.org/10.1016/j.fluid.2018.06.009

[22] Le, T. N., Phan, C. M., Nguyen, A. V., Ang, H. M. "An unusual synergistic adsorption of MIBC and CTAB mixtures at the air-water interface", Minerals Engineering, 39, pp. 255-261, 2012. https://doi.org/10.1016/j.mineng.2012.06.003

[23] Rosen, M. J., Zhao, F. "Binary Mixtures of Surfactants. The Effect of Structural and Microenvironmental Factors on Molecular Interaction at the Aqueous Solution/Air Interface", Journal of Colloid and Interface Science, 95(2), pp. 443-452, 1983.

https://doi.org/10.1016/0021-9797(83)90204-7
[24] Rosen, M. J., Zhou, Q. "Surfactant-Surfactant Interactions in Mixed Monolayer and Mixed Micelle Formation", Langmuir, 17(12), pp. 3532-3537, 2001. https://doi.org/10.1021/1a001197b

[25] Goloub, T. P., Pugh, R. J., Zhmud, B. V. "Micellar Interactions in Nonionic/Ionic Mixed Surfactant Systems", Journal of Colloid and Interface Science, 229(1), pp. 72-81, 2000. https://doi.org/10.1006/jcis.2000.6954

[26] Adamson, A. W., Gast, A. P. "Physical Chemistry of Surfaces", 6th ed., John Wiley \& Sons Inc., New York, USA, 1997.

[27] Matsubara, H., Ohta, A., Kameda, M., Villeneuve, M., Ikeda, N., Aratono, M. "Interaction between Ionic and Nonionic Surfactants in the Adsorbed Film and Micelle: Hydrochloric Acid, Sodium Chloride and Tetraethylene Glycol Monooctyl Ether", Langmuir, 15(17), pp. 5496-5499, 1999. https://doi.org/10.1021/la981769g

[28] Moore, S. A., Glenn, K. M., MacDonald, A. M., Palepu, R. M. "Micellar and associated thermodynamic properties of binary mixtures of alkyl triphenyl phosphonium bromides in ethylene glycol and water mixtures", Colloid and Polymer Science, 285(5), pp. 543-552, 2007.

https://doi.org/10.1007/s00396-006-1604-6

[29] Szymczyk, K., Zdziennicka, A., Krawczyk, J., Janczuk, B. "Mutual influence of cetyltrimethylammonium bromide and Triton X-100 on their adsorption at the water-air interface", The Journal of Chemical Thermodynamics, 59, pp. 35-42, 2013. https://doi.org/10.1016/j.jct.2012.12.004

[30] Trawinska, A., Hallmann, E., Medrzycka, K. "Synergistic effects in micellization and surface tension reduction in nonionic gemini S-10 and cationic RTAB surfactants mixtures", Colloids and Surfaces A: Physicochemical and Engineering Aspects, 488, pp. 162-172, 2016. https://doi.org/10.1016/j.colsurfa.2015.10.008 